Supporting Information

\title{
Encapsulating Red Phosphorus in Ultralarge Pore Volume Hierarchical Porous Carbon Nanospheres for Lithium/Sodium-Ion Half/Full Batteries
}

Bingqiu Liu, ${ }^{\dagger}$ Qi Zhang, ${ }^{\dagger}$ Lu Li ${ }^{*, \dagger}$ Zhanshuang Jin, ${ }^{\dagger}$ Chungang Wang, ${ }^{* \dagger}$ Lingyu Zhang ${ }^{\dagger}$ and Zhong-Min Su,

$†$ Department of Chemistry, Northeast Normal University, 5268 Renmin Street,

Changchun, Jilin, 130024, P. R. China

† School of Chemistry and Environmental Engineering, Changchun University of

Science and Technology, Changchun, 130022, China 


\section{Experiment section}

\section{Synthesis of PAA-Ca nanospheres}

In a $6 \mathrm{~L}$ conical flask, a PAA aqueous solution $\left(0.2 \mathrm{~g} \mathrm{~mL}^{-1}, 22 \mathrm{~mL}\right)$ and $1.4 \mathrm{~g}$ $\mathrm{Ca}(\mathrm{OH})_{2}$ were added in deionized water $(2 \mathrm{~L})$ and ultrasonically dispersed for $30 \mathrm{~min}$. After that, isopropyl alcohol (4 L) was dripped to the flask under magnetic stirring to obtain the PAA-Ca nanospheres. The obtained PAA-Ca nanospheres were centrifuged and washed by anhydrous ethanol and finally dried at $60{ }^{\circ} \mathrm{C}$ over night for further experiment.

\section{Synthesis of hierarchical porous carbon nanospheres}

The highly dispersed PAA-Ca nanospheres were annealed from room temperature to $700{ }^{\circ} \mathrm{C}$ at a heating rate of $2{ }^{\circ} \mathrm{C} \min ^{-1}$ and then maintained at $700{ }^{\circ} \mathrm{C}$ for $4 \mathrm{~h}$ under a high-purity argon atmosphere to obtain the $\mathrm{CaO} / \mathrm{C}$ nanospheres. After washing in $\mathrm{HCl}$ aqueous solution, the as-synthesized $\mathrm{CaO} / \mathrm{C}$ nanospheres were converted into honeycomb-like hierarchical porous carbon nanospheres (HHPCNSs).

\section{Synthesis of HHPCNSs/P mixture}

HHPCNSs/P mixture was prepared just by hand-milling HHPCNSs and red P in a mortar without $\mathrm{V}-\mathrm{C}$ process.

\section{Electrochemical Tests}

Electrochemical performances of the samples were evaluated in Li test cells. The working electrodes were fabricated by mixing active materials, acetylene black and 
polyvinylidene fluoride (PVDF) binder at a weight ratio of 8:1:1 in N-methylpyrrolidone (NMP) to form a high dispersed slurry. The slurry was then coated on a $\mathrm{Cu}$ foil and dried at $100{ }^{\circ} \mathrm{C}$ for $12 \mathrm{~h}$ in vacuo. The mass loading of the active materials was about $1.2 \mathrm{mg} \mathrm{cm}^{-2}$. The LIBs were assembled in an argon-filled glove box. Lithium metal was used as the counter electrode. The electrolyte was $1 \mathrm{M}$ $\mathrm{LiPF}_{6}$ dissolved in a 1:1 mixture of ethylene carbonate (EC) and diethyl carbonate (DEC). The discharge-charge cycling was performed within a voltage range of 0.01-2.5 V on a battery test instrument (CT2001A, LAND, China) at ambient temperature. In the case of Li-ion full cells, $\mathrm{LiFePO}_{4}$ was chosen as the active material for the cathode. The $\mathrm{LiFePO}_{4}$ electrode was prepared by mixing $80 \mathrm{wt} \%$ $\mathrm{LiFePO}_{4}, 10 \mathrm{wt} \%$ acetylene black, and $10 \mathrm{wt} \%$ PVDF dissolved in NMP to form slurry. The mixture was spread on an Al foil, which was used as a cathode after drying. In this study, the specific capacity ratio of anode material (HHPCNSs/P composite) to cathode material $\left(\mathrm{LiFePO}_{4}\right)$ in the lithium-ion full cell was about 1:1.1. The HHPCNSs/P composite half-cell was first assembled and cycled 5 times to form a stable SEI film before assembling the full-cells. The SIBs were fabricated using sodium metal foil as the counter electrode, and $1.0 \mathrm{M} \mathrm{NaClO}_{4}$ salt in EC: diethyl carbonate (DEC) $(1: 1)$ as the electrolyte. Discharge/charge tests were performed between $0.01-2.5 \mathrm{~V}$ vs. $\mathrm{Na}^{+} / \mathrm{Na}$ at various rates on a LAND battery test instrument (CT2001A). CV was implemented on a CHI760E electrochemical workstation at a scan rate of $0.1 \mathrm{mV} \mathrm{s}^{-1}$ between 0.01 and $2.5 \mathrm{~V}$. AC electrochemical impedance spectra (EIS) were obtained on a CHI760E electrochemical workstation in the 
frequency range of $100 \mathrm{kHz}$ to $0.01 \mathrm{~Hz}$. Besides, the Na-ion full cell performances were tested by using HNPCNCs-N-800 and $\mathrm{Na}_{3} \mathrm{~V}_{2}\left(\mathrm{PO}_{4}\right)_{3}$ as anode and cathode, respectively. The $\mathrm{Na}_{3} \mathrm{~V}_{2}\left(\mathrm{PO}_{4}\right)_{3}$ electrode was prepared by mixing $70 \mathrm{wt} \%$ $\mathrm{Na}_{3} \mathrm{~V}_{2}\left(\mathrm{PO}_{4}\right)_{3}, 20 \mathrm{wt} \%$ acetylene black, and $10 \mathrm{wt} \%$ PVDF dissolved in NMP to form slurry. The mixture was spread on an Al foil, which was used as a cathode after drying. In this study, the specific capacity ratio of anode material (HHPCNSs/P composite) to cathode material $\left(\mathrm{Na}_{3} \mathrm{~V}_{2}\left(\mathrm{PO}_{4}\right)_{3}\right)$ in the sodium-ion full cell was about 1:(1.05-1.1). The HHPCNSs/P composite half-cell was first assembled and cycled 5 times to form a stable SEI film before assembling the full-cells.

\section{Materials and characterizations}

Poly (acrylic acid) (PAA, $\mathrm{M}_{\mathrm{W}} \approx 1800$ ) was purchased from Sigma-Aldrich (USA). Red phosphorus (P, 98.5\%) was obtained from Energy Chemical. Calcium hydroxide $\left(\mathrm{Ca}(\mathrm{OH})_{2}, 95.0 \%\right)$, carbon disulfide $\left(\mathrm{CS}_{2}, 99.7 \%\right)$, anhydrous ethanol and isopropyl alcohol (IPA) were obtained from Sinopharm Chemical Reagent Beijing Co., Ltd and used without further purification. Deionized water was used in all experiments. Transmission electron micrographs (TEM) were taken by JEOLJEM-2100F transmission electron microscope under a $200 \mathrm{kV}$ accelerating voltage. High-resolution TEM (HRTEM) characterizations were recorded by a TECNAI G2 F20 transmission electron microscope under $200 \mathrm{kV}$ accelerating voltage. Scanning electron microscopy (SEM) images were obtained by using an XL30 ESEM-FEG field-emission scanning electron microscope (FEI Co.). X-ray diffraction (XRD) patterns were obtained on a D8 Focus diffractometer with $\mathrm{Cu}$ K $\alpha$ radiation. XPS was 
performed with an ECSALAB 250 by using non-monochromated Al Ka radiation. Raman spectra were recorded at room temperature with a JY HR-800 LabRam confocal Raman microscope in a backscattering configuration, with an excitation wavelength of $325 \mathrm{~nm}$. X-ray photoelectron spectroscopy (XPS) analyses were performed on X-ray photoelectron spectrophotometer (ESCALABMKLL) from VG. $\mathrm{N}_{2}$ adsorption-desorption measurements were measured using an intelligent gravimetric analyser Autosorb-iQ (Quantachrome).

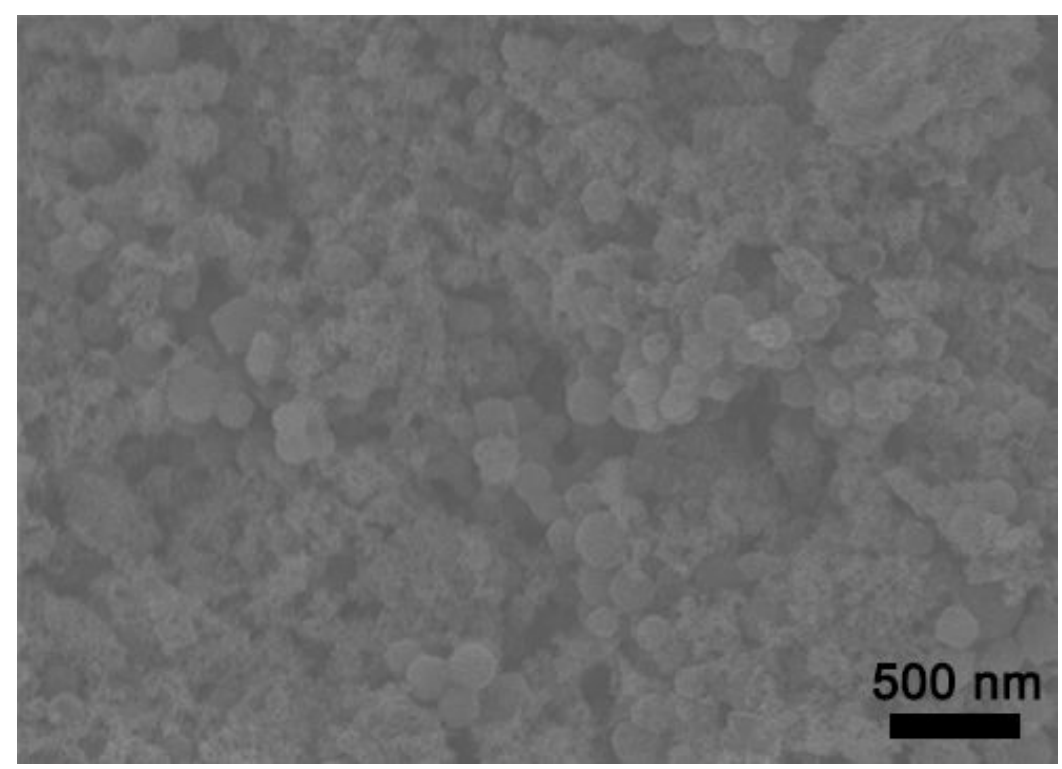

Figure S1. SEM image of HHPCNSs/P mixture. 


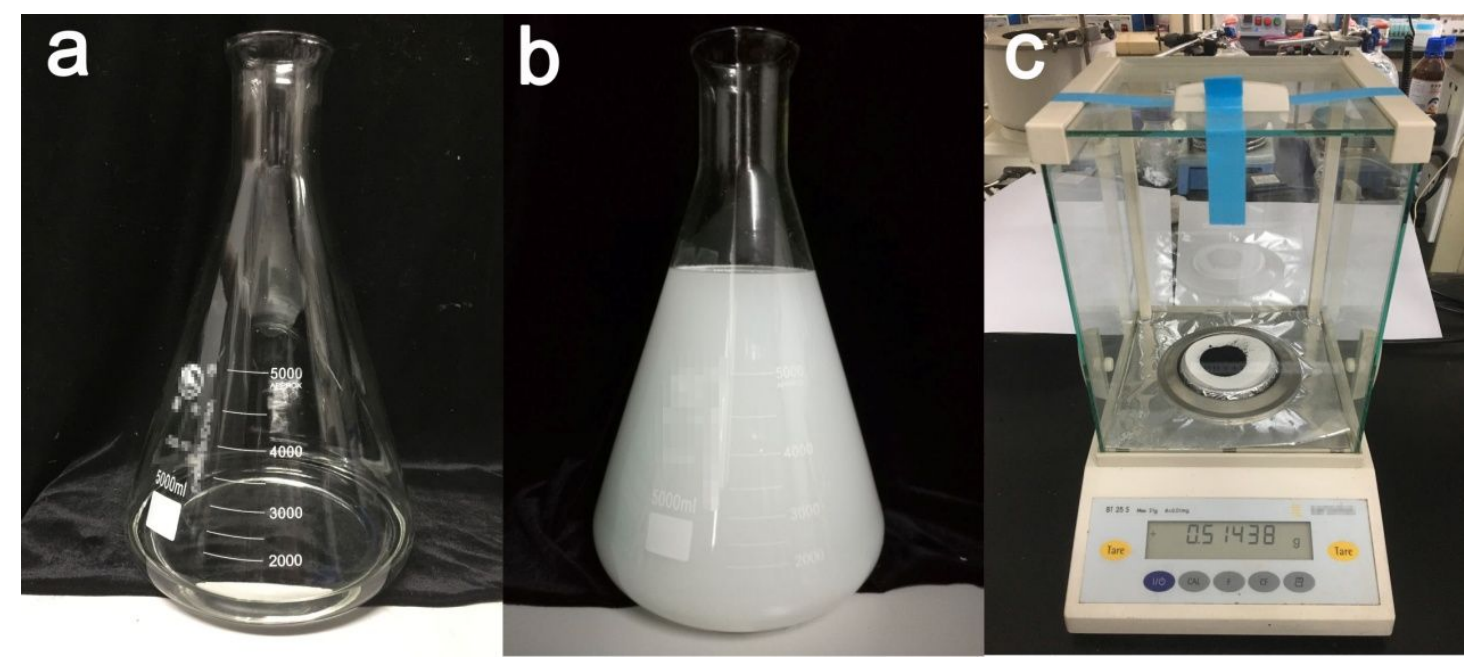

Figure S2. Photographs of (a) PAA-Ca aqueous solution, (b) PAA-Ca solution after adding IPA and (c) the weight of HHPCNSs powder.

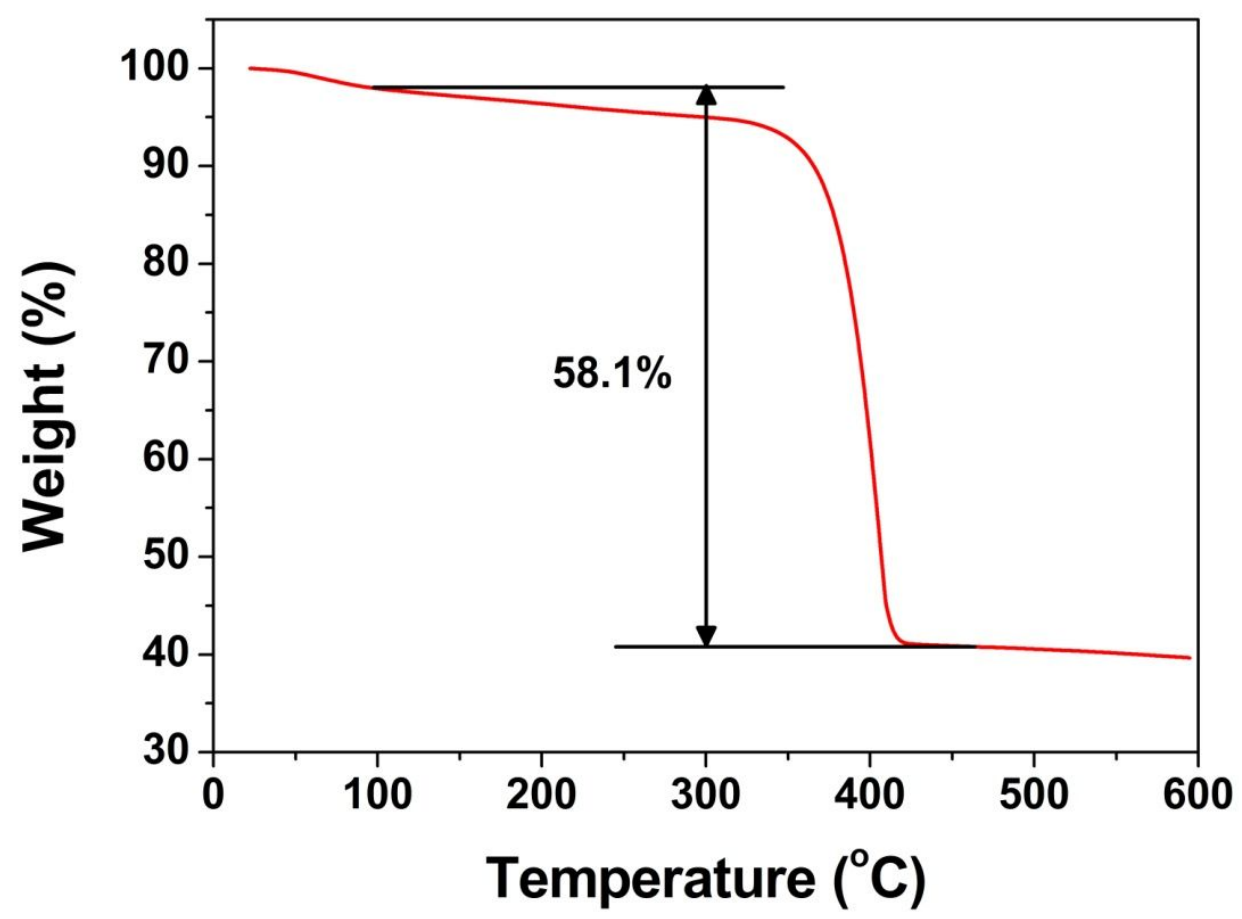

Figure S3. TGA curve of HHPCNSs/P composite. 


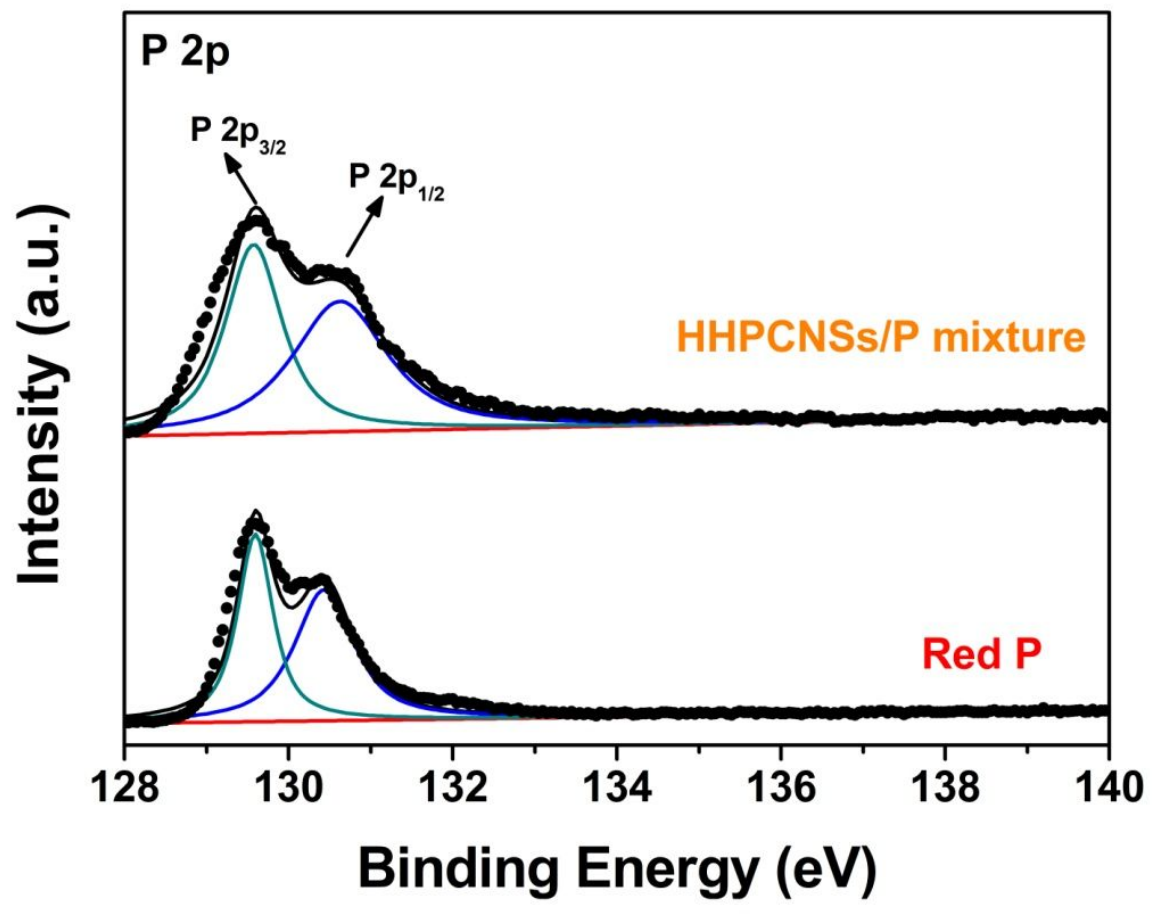

Figure S4. High-resolution P 2p XPS spectra of red P and HHPCNSs/P mixture.
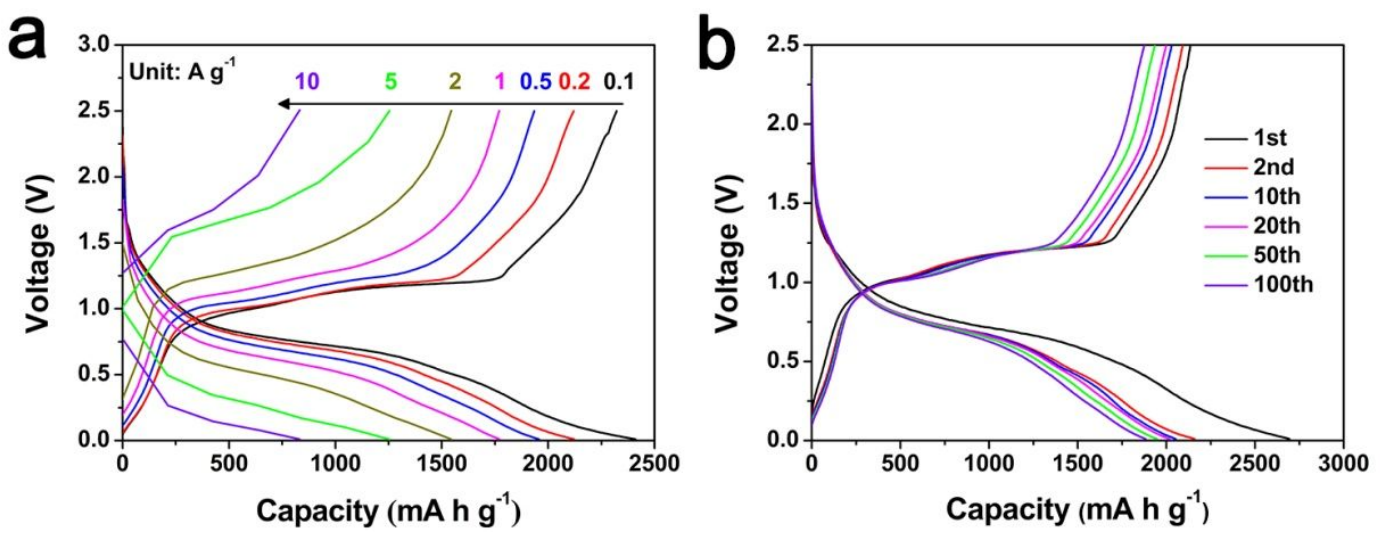

Figure S5. (a) Corresponding charge/discharge profiles of HHPCNSs/P composite at various current densities and (b) discharge-charge voltage profiles of HHPCNSs/P composite after various cycle numbers at $0.5 \mathrm{~A} \mathrm{~g}^{-1}$ for $\mathrm{Li}$-ion batteries. 


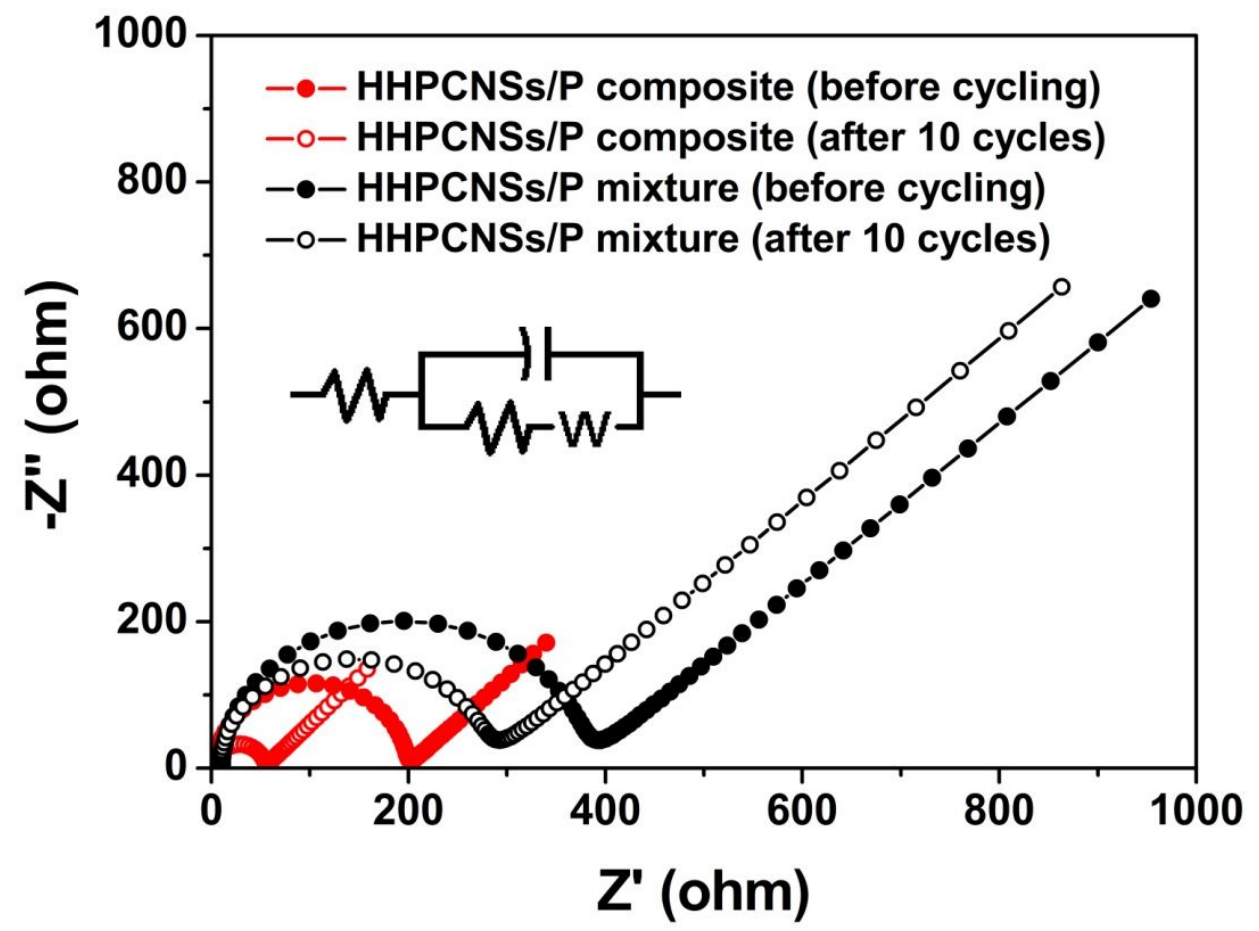

Figure S6. EIS spectra of HHPCNSs/P composite and mixture before cycling and after 10 cycles for LIBs.
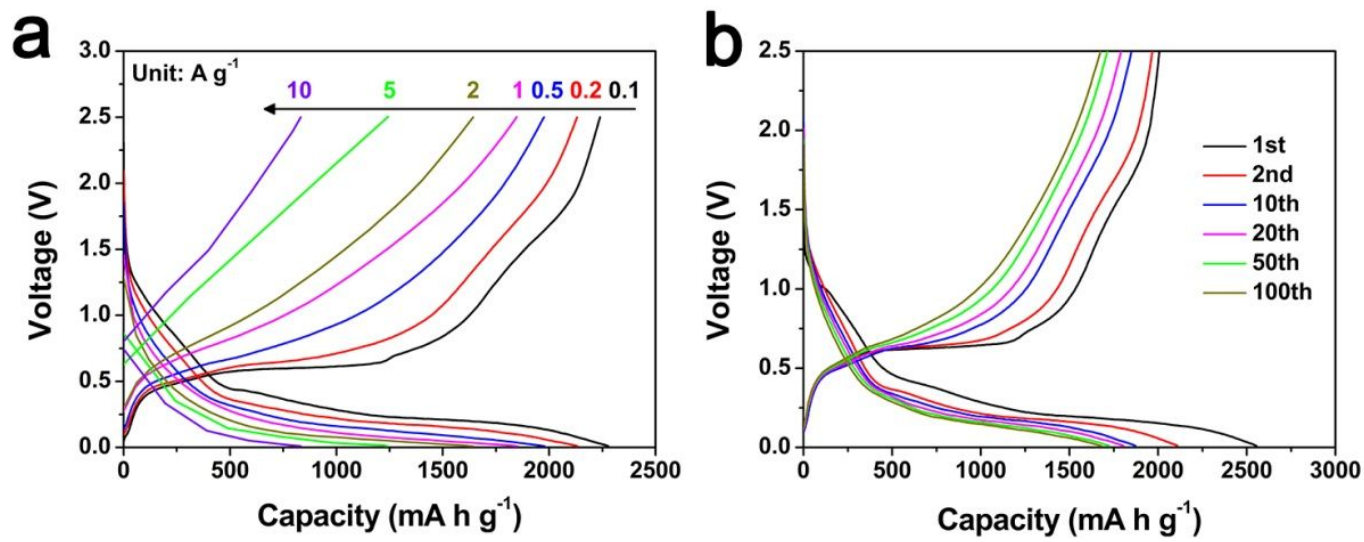

Figure S7. (a) Corresponding charge/discharge profiles of HHPCNSs/P composite at various current densities and (b) discharge-charge voltage profiles of $\mathrm{HHPCNSs} / \mathrm{P}$ composite after various cycle numbers at $0.5 \mathrm{~A} \mathrm{~g}^{-1}$ for $\mathrm{Na}$-ion batteries. 


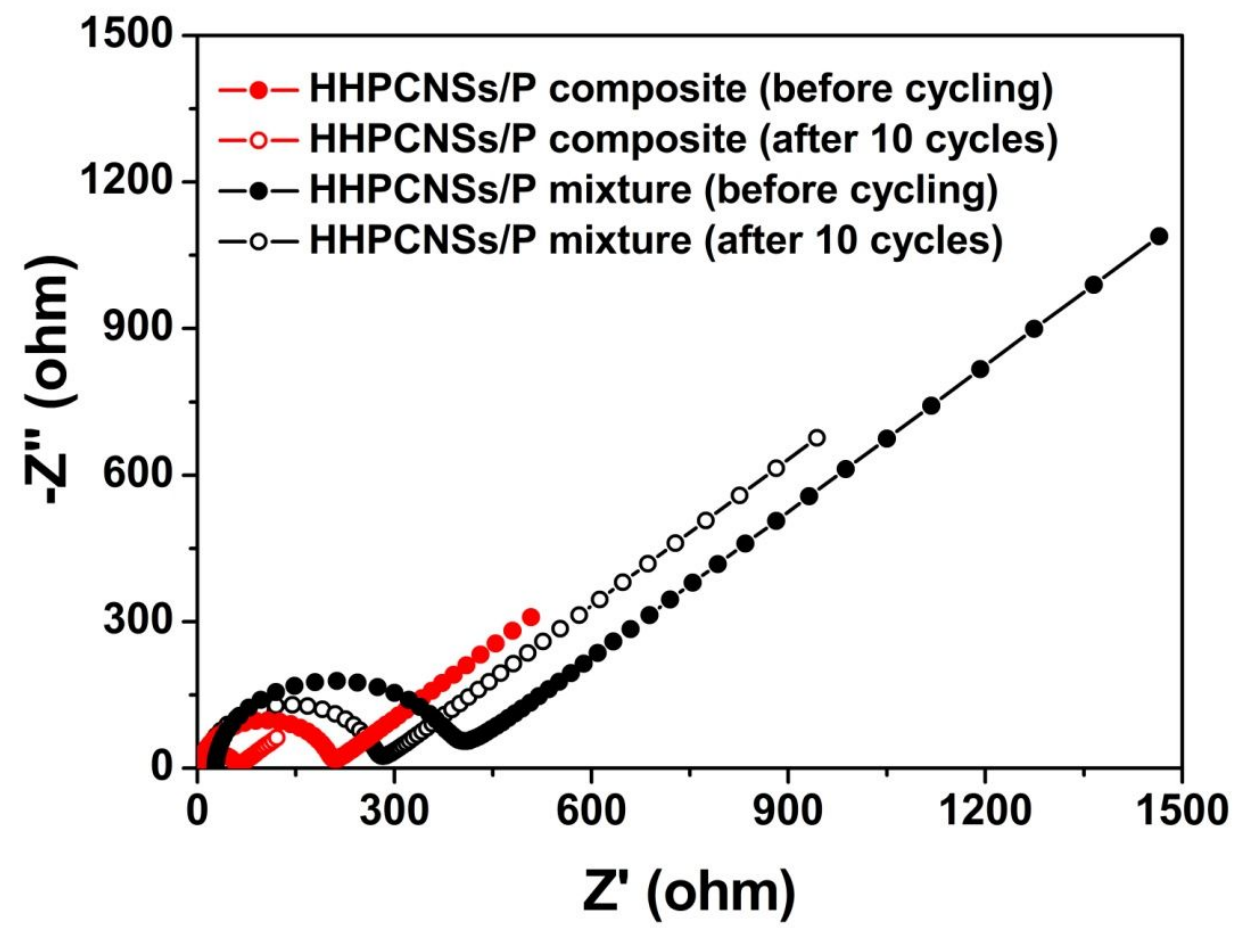

Figure S8. EIS spectra of HHPCNSs/P composite and mixture before cycling and after 10 cycles for SIBs. 

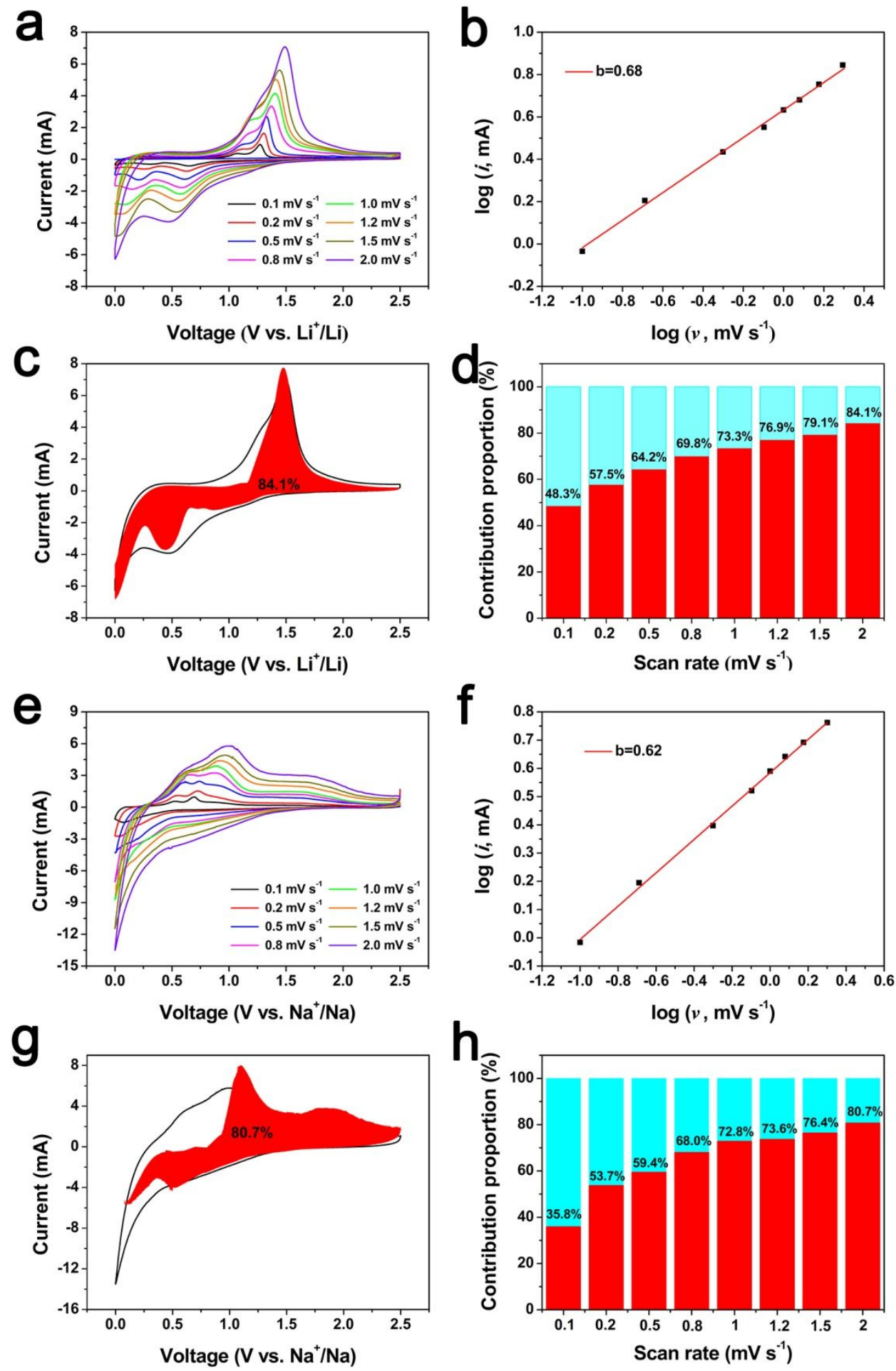

Figure S9. (a),(e) $\mathrm{CV}$ curves at various scan rates of 0.1 to $2 \mathrm{mV} \mathrm{s}^{-1}$ for LIBs/SIBs. (b),(f) $\log (i)-\log (v)$ curves (b-value determination) for LIBs/SIBs. (c), (g) Contribution proportion of HHPCNSs/P composite at $2 \mathrm{mV} \mathrm{s}^{-1}$ for LIBs/SIBs. (d),(h) Contribution proportion of HHPCNSs/P composite at different scan rates for LIBs/SIBs. 

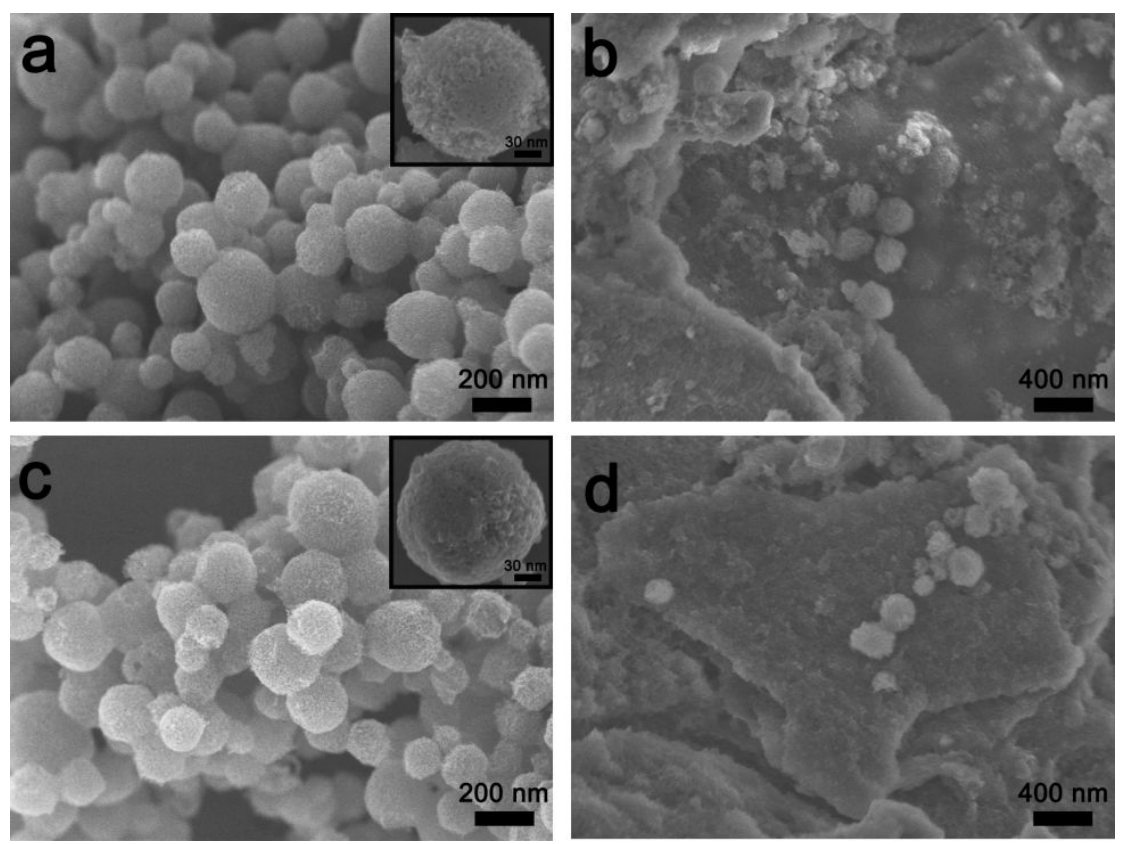

Figure S10. SEM images of (a) HHPCNSs/P composite and (b) HHPCNSs/P mixture after 100 cycles at $0.5 \mathrm{~A} \mathrm{~g}^{-1}$ for LIBs, (c) HHPCNSs/P composite and (d) HHPCNSs/P mixture after 100 cycles at $0.5 \mathrm{~A} \mathrm{~g}^{-1}$ for SIBs.
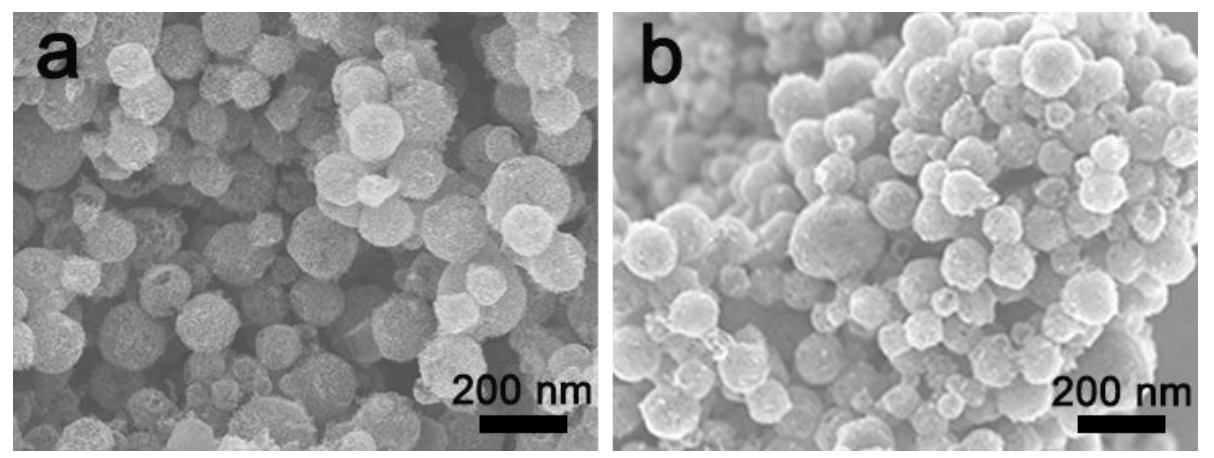

Figure S11. SEM images of (a) HHPCNSs/P composite after 1000 cycles at $5 \mathrm{~A} \mathrm{~g}^{-1}$ for LIBs and (b) HHPCNSs/P composite after 1000 cycles at $5 \mathrm{~A} \mathrm{~g}^{-1}$ for SIBs. 
Table S1. Specific surface area, pore volume and electrochemical performance of the recently reported carbon materials.

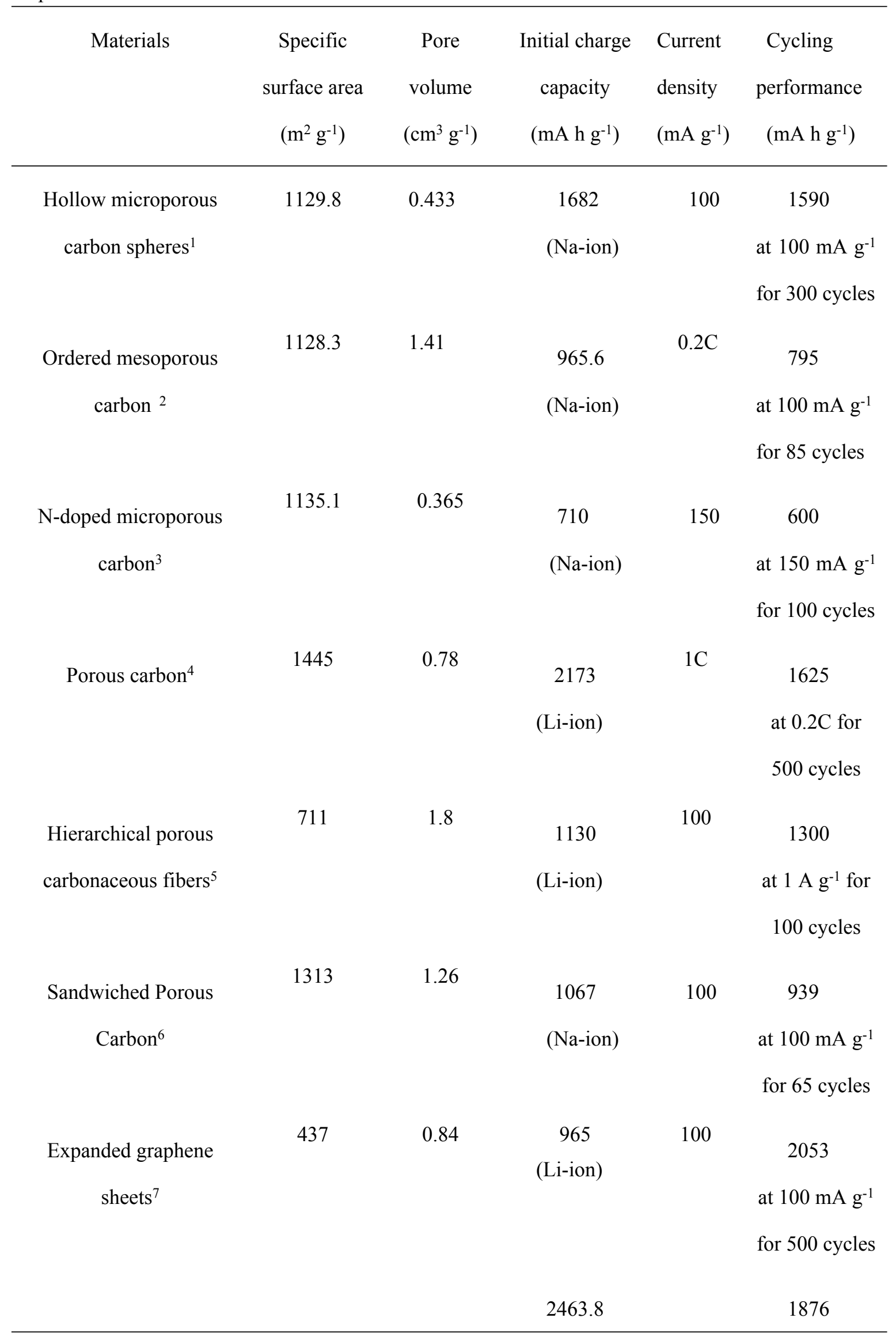


This work

$\begin{array}{ccc} & \text { (Li-ion) } & \text { at } 500 \mathrm{~mA} \mathrm{~g}^{-1} \\ & & \\ 2367.6 & \text { for } 100 \text { cycles } \\ \text { (Na-ion) } & \text { (Li-ion) } \\ & 10075 \\ & \text { at } 500 \mathrm{~mA} \mathrm{~g}^{-1} \\ & \text { for } 100 \mathrm{cycles} \\ & \text { (Na-ion) }\end{array}$

\section{References}

(1) Yao, S.; Cui, J.; Huang, J.; Huang, J.-Q.; Chong, W. G.; Qin, L.; Mai, Y.-W.; Kim, J.-K. Rational Assembly of Hollow Microporous Carbon Spheres as P Hosts for Long-Life Sodium-Ion Batteries. Adv. Energy Mater. 2018, 8, 1702267.

(2) Li, W.; Yang, Z.; Li, M.; Jiang, Y.; Wei, X.; Zhong, X.; Gu, L.; Yu, Y. Amorphous Red Phosphorus Embedded in Highly Ordered Mesoporous Carbon with Superior Lithium and Sodium Storage Capacity. Nano Lett. 2016, 16, 1546-1553

(3) Li, W.; Hu, S.; Luo, X.; Li, Z.; Sun, X.; Li, M.; Liu, F.; Yu, Y. Confned Amorphous Red Phosphorus in MOF-Derived N-Doped Microporous Carbon as a Superior Anode for Sodium-Ion Battery. Adv. Mater. 2017, 29, 1605820

(4) Sun, Y.; Wang, L.; Li, Y.; Li, Y.; Lee, H. R.; Pei, A.; He, X.; Cui, Y. Design of Red Phosphorus Nanostructured Electrode for Fast-Charging Lithium-Ion Batteries with High Energy Density. Joule 2019, 3, 1080-1093.

(5) Xu, T.; Li, D.; Chen, S.; Sun, Y.; Zhang, H.; Xia, Y.; Yang, D. Nanoconfinement

of Red Phosphorus Nanoparticles in Seaweed-Derived Hierarchical Porous 
Carbonaceous Fibers for Enhanced Lithium Ion Storage. Chem. Eng. J. 2018, 345, 604-610.

(6) Wu, Y.; Liu, Z.; Zhong, X.; Cheng, X.; Fan, Z.; Yu, Y. Amorphous Red Phosphorus Embedded in Sandwiched Porous Carbon Enabling Superior Sodium Storage Performances. Small 2018, 14, e1703472.

(7) Ruan, J.; Pang, Y.; Luo, S.; Yuan, T.; Peng, C.; Yang, J.; Zheng, S. Ultrafine Red

P Nanoconfined between Expanded Graphene Sheets for High-Performance Lithium-Ion Batteries. J. Mater. Chem. A 2018, 6, 20804-20812. 